Аолгалёв И. В., Бразовская Н. Г., Иванова А. Ю., Шипхинеева А. Ю., Богайчук П. М. ФГБОУ ВО «Сибирский госуАарственный медицинский университет» МинзАрава России, 634050, Томск, Московский тракт, 2

ВАИЯНИЕ АРТЕРИААЬНОЙ ГИПЕРТЕНЗИИ,

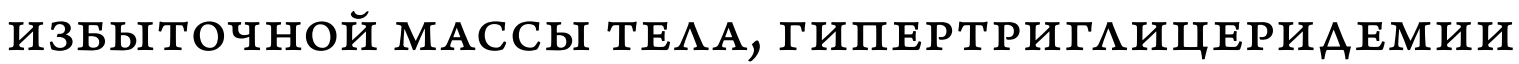
И ИХ СОЧЕТАНИЯ НА СМЕРТНОСТЬ ПО РЕЗУАЬТАТАМ 27-АЕТНЕГО КОГОРТНОГО ПРОСПЕКТИВНОГО ИССАЕАОВАНИЯ

КАючевые слова: артериамьная гипертензия; избыточная масса тела; гипертриглицеридемия; сердечно-сосудистые забомевания; смертность

Ссылка дяя цичтирования: Аолгалёв И. В., Бразовская Н. Г., Иванова А. Ю., Шипхинеева А. Ю., Богайчук П. М. Влияние артериальной гипертензии, избыточной массы тела, гипертриглицеридемии и их сочетания на смертность по результатам 27-летнего когортного проспективного исследования. Кардиология. 2019;59(11S):44-52

PЕзюме

Цель. Изучить влияние артериальной гипертензии (АГ), избыточной массы тела (ИзбМТ), гипертриглицеридемии (ГТГ) и их сочетания на формирование риска общей и сердечно-сосудистой (СС) смертности. Материалы и методы. В 27-летнем проспективном когортном исследовании неорганизованной попумяции г. Томска (1546 человек в возрасте 20-59 мет - 916 женщин и 630 мужчин) изучена распространенность АГ, ИзбМТ и ГТГ (1988-1991 гг.) и их прогностическая значимость в формировании риска смертности от всех причин и от СС заболеваний (ССЗ) (2015 г.). К АГ относили уровень артериального Аавления $\geq 140 / 90$ мм рт. ст., к ИзбМТ индекс массы тела (ИМТ) $\geq 25,0$ кг $/ \mathrm{m}^{2}$, к ГТГ - уровень триглицеридов (ТГ) сыворотки $\geq 1,7$ ммоль $/$ м. Результаты. Выявлено влияние АГ на формирование общей (относительный риск $(\mathrm{OP})=2,2)$ и СС $(\mathrm{OP}=3,38)$ смертности, что отмечалось во всех поло-возрастных группах, кроме мужчин 40-59 ^ет, у которых результаты, касающиеся смертности от ССЗ оказались статистически незначимыми. Показано, что АГ оказывает значимое независимое влияние на формирование риска прежАевременной смертности. ОР общей смерт-

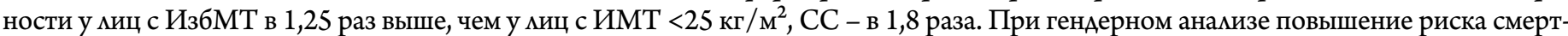
ности наблюАалось среди женщин с ИзбМТ, в большей степени за счет млаАшей (20-39 мет) возрастной группы. ГТГ увеличивает ОР общей смертности в 1,46 раз, СС - в 2,15 раза, преимущественно за счет старшей (40-59 мет) возрастной группы. ГТГ оказамась значимым фактором риска в формировании смертности только у женщин. Сочетание АГ и ИзбМТ увеличивает ОР смертности от всех причин в 2,23 раза, от СС 3 - в 4,0 раза; АГ и ГТГ - в 2,83 и 5,06 раз; ИзбМТ и ГТГ - в 1,73 и 2,99 раза соответственно. Повышенный уровень ТГ у миц с ИзбМТ дополнительно увеличивает риск общей смертности в 1,53 раза, СС смертности - в 2,18 раза по сравнению с лицами, имеющими ИзбМТ без ГТГ (р<0,05); в 1,51 и 2,04 раз соответственно - у лиц с АГ по сравнению с лицами без АГ $(\mathrm{p}<0,05)$. Аополнительный риск общей смертности от ИзбМТ у лиц с АГ выявлен только уженщин $(\mathrm{OP}=3,23)$. 3aключение. По результатам 27-летнего проспективного исследования установлено независимое влияние АГ на формирование риска общей и СС смертности. Сочетание АГ с ГТГ увеличивает риск смертности от всех причин в 2,8 раза, от СС3 - в 5,1 раз; АГ и ИзбМТ - в 2,2 и 4 раза, ГТГ и ИзбМТ - в 1,7 и 3 раза соответственно. Выявлен дополнительный риск общей смертности в связи с ГТГ у лиц с ИзбМТ $(\mathrm{OP}=1,5)$ и $\mathrm{AГ}(\mathrm{OP}=1,5)$, а также дополнительный риск СС смертности от ГТГ у миц с ИзбМТ $(\mathrm{OP}=2,2)$ и $\mathrm{A \Gamma}(\mathrm{OP}=2,0)$.

Dolgalev I. V., Brazovskaya N. G., Ivanova A. Yu., Shipkhineeva A. Yu., Bogajchuk P. M. Siberian State Medical University, Moskovsky trakt, 2, Tomsk, Russian Federation, 634050

\title{
IMPACT OF HYPERTENSION, OVERWEIGHT, HYPERTRIGLYCERIDEMIA AND THEIR COMBINATION FOR MORTALITY RATE ACCORDING TO THE RESULTS OF A 27-YEAR COHORT PROSPECTIVE STUDY
}

Keywords: hypertension, overweight, hypertriglyceridemia, cardiovascular diseases, mortality

For citation: Dolgalev I. V., Brazovskaya N. G., Ivanova A.Yu., Shipkhineeva A. Yu., Bogajchuk P. M. Impact

of hypertension, overweight, hypertriglyceridemia and their combination for mortality rate according

to the results of a 27-year cohort prospective study. Kardiologiia. 2019;59(11S):44-52

SUMMARY

Aim. To study influence of hypertension, overweight, hypertriglyceridemia and their combinations for all-cause and cardiovascular mortality risk formation. Methods. The prevalence of hypertension, overweight and hypertriglyceridemia was studied (1988-1991) by 27-year prospective cohort study of unorganized population of Tomsk ( 1546 persons - 916 female and 630 male). The predictive value of these risk factors for all-cause and cardiovascular mortality risk formation were researched in 2015 . Hypertension was diagnosed in persons with blood pressure greater or equal to $140 / 90 \mathrm{~mm} \mathrm{Hg}$, overweight was diagnosed in people with body mass index greater or equal $25 \mathrm{~kg} / \mathrm{m}^{2}$, hypertriglyceri- 
demia was diagnosed in individuals having high blood level of triglycerides (greater or equal to 1.7). Results. Influence of hypertension for all-cause (relative risk (RR) 2.2) and cardiovascular mortality (RR 3.38) risk formation was detected. A hypertension related elevation of mortality risk was observed both among women and men and in all age groups with the exception of men 40-59 years (the results for cardiovascular mortality in these persons was statistically insignificant). We established that hypertension had the independent significant contribution for mortality risk formation. It is shown that RR of all-cause mortality 1.25 times (cardiovascular mortality 1.8 times) more in overweight persons. Increase of relative mortality risk was detected in overweight women, especially in women 20-39 years old. Hypertriglyceridemia increases relative risk of all-cause mortality 1.46 times, relative risk of cardiovascular mortality 2.15 times, especially in individuals $40-59$ years old. It was revealed that hypertriglyceridemia is significant risk factor for all-cause mortality formation only in women. Combination of hypertension and overweight increases the risk of all-cause mortality 2.23 times and the risk of cardiovascular mortality 4.0 times, combination of hypertension and hypertriglyceridemia -2.83 and 5.06 times, combination of overweight and hypertriglyceridemia - 1.73 and 2.99 times, respectively. We detected the additional risk of hypertriglyceridemia in individuals with overweight for all-cause (RR 1.53) and cardiovascular (RR 2.18) mortality risk formation compared with overweight persons with normal level of triglycerides and also the additional risk of hypertriglyceridemia (RR 1.51 and 2.04, respectively) in individuals with hypertension compared with normotensive persons ( $<<0,05)$. The additional risk of overweight in individuals with hypertension for all-cause mortality was found only in women (RR 3.23). Conclusion. The independent significant impact of hypertension for all-cause and cardiovascular mortality risk formation was revealed by the results of 27 -year prospective study. Combination of hypertension and hypertriglyceridemia increases the risk of all-cause mortality 2.8 times and the risk of cardiovascular mortality 5.1 times, combination of hypertension and overweight -2.2 and 4 times, combination of overweight and hypertriglyceridemia - 1.7 and 3 times, respectively. We detected the additional risk of hypertriglyceridemia for all-cause mortality in overweight people (RR 1.5) and in individuals with hypertension (RR 1.5). Also, the additional risk of hypertriglyceridemia for cardiovascular mortality risk formation in overweight people (RR 2.2) and in persons with hypertension (RR 2.0) was found.

Information about the corresponding author: Ivanova A.Y., a181288@yandex.ru

\section{Введение}

Сердечно-сосудистые заболевания (СС3) - главная причина смертности в мире. Около 1/3 от общего числа смертей обусловлено этой причиной (17,9 млн человек в гоА). Важнейшими модифицируемыми ФР ССЗ явмяются артериамьная гипертензия (АГ), избыточная масса тела (ИзбМТ) и Аислипопротеидемии. АГ имеет широкую распространенность среди населения (примерно 40\% в мире и $37,8 \%$ в России) и обусловливает около 9,4 млн смертей в гоА [1-3]. По причинам, связанным с ИзбМТ, ежегодно умирают около 2,8 млн человек [4]. В последние годы наблюдается увеличение распространенности ИзбМТ среАи населения. В 2016 году более 1,9 мира взрослых старше 18 мет (39\% взрослого насемения) имели избыточный вес, из них свыше 650 (13\%) млн страдали ожирением, что более чем в три раза превышает показатели 1975 г. [5]. Не меньшую распространенность этот ФР имеет и в России, гАе в 2010-2012 гг. 60\% мужчин и 59,2\% женщин имели ИзбМТ [6].

Известно, что АислипопротеиАемии, в частности повышенный уровень общего ХС и мипопротеиАов низкой плотности, увекичивают риск развития ССЗ и СС смертности [7]. При этом гиперТГ (ГТГ) Аолгие годы остается неоднозначным ФР ССЗ. ОАнако в послеАнее время появились сведения о наличии самостоятельного негативного влияния повышенного уровня ТГ на развитие заболеваний СС системы [8]. А поскольку ГТГ высоко распространена (30\% населения в США, 29,2\% - в России), можно преАполагать, что она вносит значительный вклаА в формирование попумяционного риска смертности $[9,10]$.

Информация о сочетанном воздействии АГ, ИзбМТ и ГТГ на формирование смертности в отечественной митературе отсутствует, а проблема влияния каждого из ФР в отАельности по результатам Алительных проспективных исследований освещена в еАиничных публикациях. В этой связи изучение Аанного вопроса преАставляет несомненный интерес.

Цемь: изучение влияния АГ, ИзбМТ, ГТГ и их сочетания на формирование риска смертности от ССЗ и от всех причин по результатам 27-метнего проспективного когортного исслеАования неорганизованной попуяяции.

\section{Материалы и методы}

Проведено 27-летнее когортное проспективное исследование неорганизованной попумяции г. Томска. Формирование выборки осуществцялось по спискам квартир

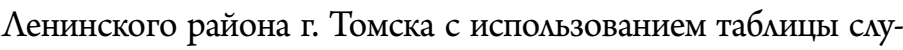
чайных цифр. Этот район выбран аля проведения исследования, так как является типичным районом г. Томска с позиций эпидемиологической характеристики. Всего обследовано 1546 человек в возрасте 20-59 мет, из них 916 женщин и 630 мужчин. Исследование проводилось в соответствии с принципами Хемьсинкской Аекларации. На первом этапе, выполненном в 1988-1991 гг., изучахась распространенность АГ, ИзбМТ и ГТГ. Аля выявмения АГ проводилось измерение AА ртутным сфигмоманометром со стандартной манжетой по методу Короткова Авукратно с 5-минутным интервалом, после чего рассчитывался среАний показатель САА и ААА. АГ Аиагностировалась при уровне АА $\geq 140 / 90$ ммрт.ст. Аля оценки массы тела рассчитывался ИМТ (ИМТ = масса тела (кг)/рост $\left.(\text { м })^{2}\right)$, к ИзбМТ относики случаи с ИМТ $\geq 25,0$ кг $/ \mathrm{м}^{2}$. С цемью выявления ГТГ проводилось биохимическое исследование крови (утром, натощак, спустя не менее 12 часов после последнего приема пищи). ГТГ Аиагностировалась при выявлении у обследуемого уровня ТГ $\geq 1,7$ ммоць $/ \Lambda[11]$.

В 2015 г. изучались показатели общей и СС смертности, осуществлялась оценка прогностической значимости конвен- 
ционных ФР, в том числе АГ, ИзбМТ, ГТГ и их комбинации, в формировании смертности. Причина смерти устанавливамась по материалам Архива Комитета ЗАГС ААминистрации Томской области. НаблюАение и сбор информации о жизненном статусе осуществмялись с момента первичного обслеАования до наступления «конечной точки» Амя умерших ими Ао конца 2015 г. Аля живых. Жизненный статус опредемен Аля 97,09\% участников обследования, информация о 45 респондентах отсутствовала, то есть доля утери составила 2,9\%. За 27 мет наблюдения выявлено 330 скучаев смерти, в том числе 142 - от кардиоваскулярных причин.

Анализируемая база данных сформирована в программе «Microsoft Excel 2003». Статистическая обработка осуществцялась с помощью пакета программ «Statistica 6.0», «KRelRisk 1.0». Полученные сведения описаны путем построения и анализа таблиц сопряженности с указанием абсолютных и относительных частот встречаемости признаков, Аля проверки значимости связи межАу переменными использовался критерий $\chi^{2}$ Пирсона и тест Фишера. При $\mathrm{p}<0,05$ различия считались статистически значимыми. Многофакторный анализ выполнен с помощью программы «IBM SPSS Statistics» на основе регрессионной модели пропорциональных интенсивностей Кокса. Аополнительный риск смертности определялся как величина, показывающая во сколько раз увеличивается риск преждевременной смертности при сочетании с одним изучаемым ФР Аругого предиктора, а также позвомяющая оценить достоверность влияния этого дополнительного предиктора на формирование смертности наряду с основным изучаемым ФР.

\section{Резумьтаты}

По итогам 27-летнего проспективного наблюдения установлено несомненное вмияние АГ на формирование общей (относительный риск $(\mathrm{OP})=2,2)$ и СС $(\mathrm{OP}=3,38)$ смертности, что наблюдалось во всех поло-возрастных группах за искмючением мужчин 40-59 мет, у которых показатели риска СС смертности оказались статистически незначимыми [12].

Обнаружено, что ИзбМТ также оказывает значимое вмияние на формирование смертности, увекичивая ОР общей смертности в 1,25 раз по сравнению с иицами, имеющими нормальную массу тела $(\mathrm{p}<0,05), \mathrm{CC}$ - в 1,8 раза. ОАнако при генАерном анализе повышение риска смертности от всех причин наблюдалось только у женщин, имеющих ИзбМТ (OP=2,43; $\mathrm{p}<0,001)$, в большей степени за счет мкаАшей (20-39 мет) возрастной группы $(\mathrm{OP}=2,43 ; \mathrm{p}<0,01)$. Результаты близкие этим получены и в отношении СС смертности [13]

ГиперТГ увекичивает ОР общей смертности в 1,59 раз, СС - в 2,15 раза по сравнению с мицами с исходно нормальным уровнем ТГ $(\mathrm{p}<0,001)$. При анализе по возрастным группам повышение ОР смертности от всех причин наблюАамось только в старшей возрастной группе $(\mathrm{OP}=1,36 ; \mathrm{p}<0,05)$, а при гендерном анализе - только среди женщин $(\mathrm{OP}=1,95$; $\mathrm{p}<0,01)$. Схожие результаты покучены и в отношении СС смертности.

С целью изучения степени влияния исследуемых ФР на смертность, наряду с Аругими конвенционными ФР, такими как ИБС, курение, потребление алкогомя, гиперхолестеринемия, гипоаньфахолестеринемия, пом и возраст, быи про-

Таблица 1. Относительный риск общей смертности у миц с сочетанием АГ и ИзбМТ

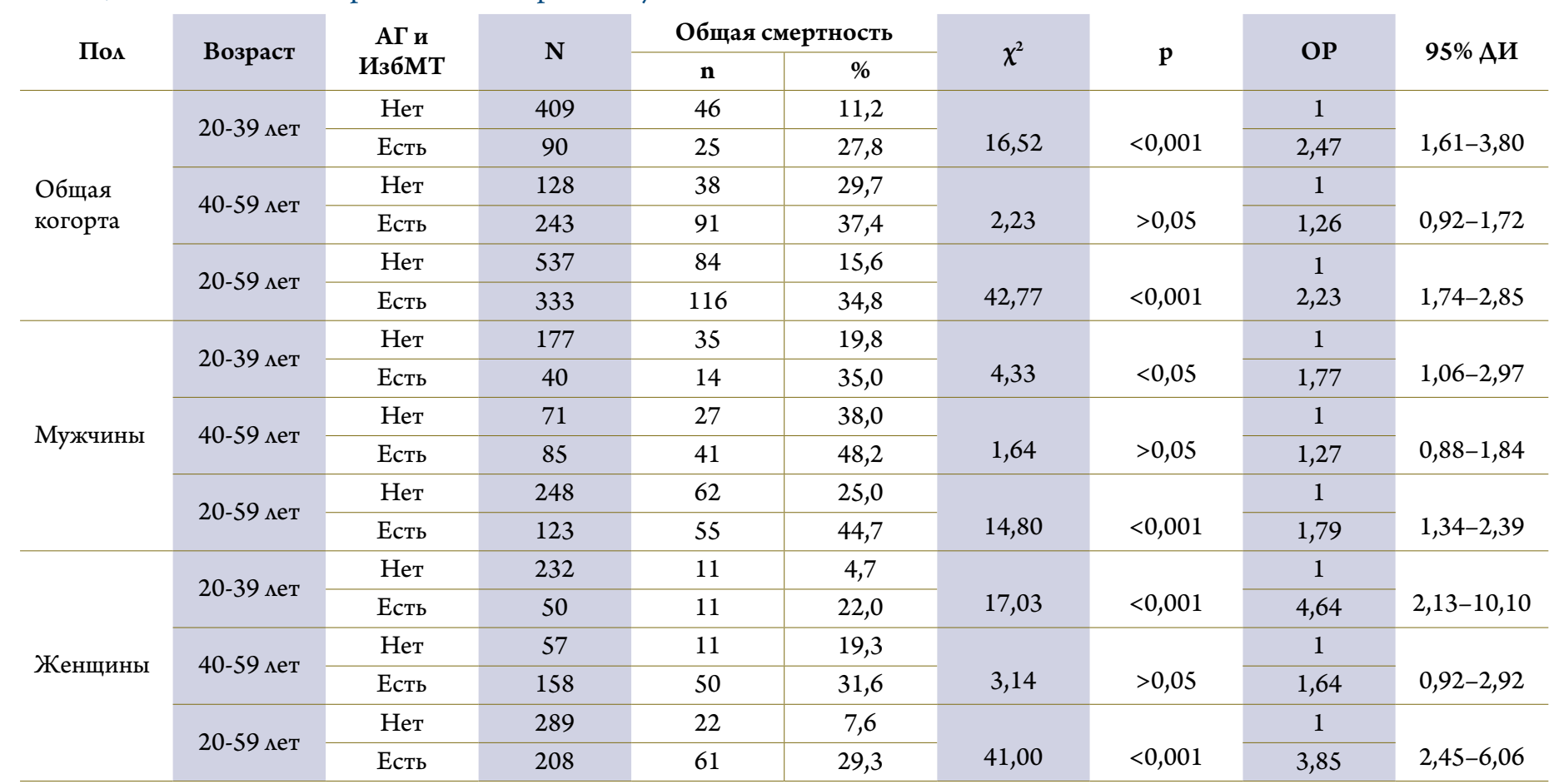

3Аесь и Аалее ОР - относительный риск; АИ - Аоверительный интервац,

$\mathrm{N}$ - общее количество миц с Аанным статусом ФР, $\mathrm{n}$ - количество умерших, $\chi^{2}$ - хи-кваАрат, $\mathrm{p}$ - уровень статистической значимости. 
Таблица 2. Относительный риск серАечно-сосудистой смертности у миц с сочетанием АГ и ИзбМТ

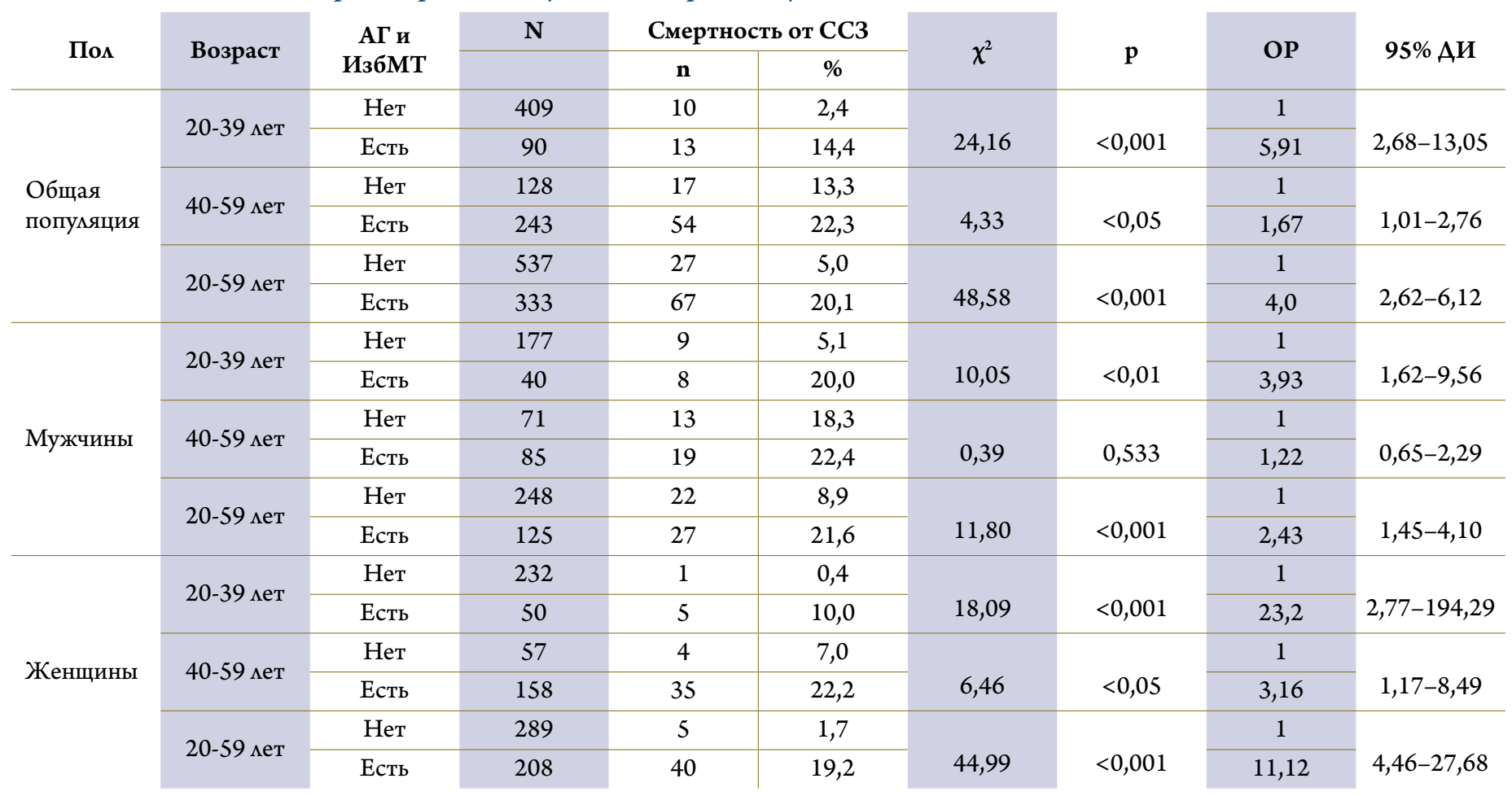

веден многофакторный анализ, который показац, что ИзбМТ и ГТГ не оказывают самостоятельного значимого вмияния на формирование общей и СС смертности ( $>>0,05)$, в то время как АГ оказалась одним из наиболее вмиятельных ФР, наряАу с курением и частым потреблением алкогомя.

Сочетание АГ и ИзбМТ увеличивает риск прежАевременной смертности в 2,23 раза (в 1,79 раза среди мужчин и в 3,85 раза среди женщин, $\mathrm{p}<0,001)$. При возрастном анализе увемичение ОР общей смертности у миц с АГ и ИзбМТ наблюАалось в миадших возрастных группах, а в группах 40-59 мет результаты носили случайный характер (табл. 1). Риск СС смертности у миц с сочетанием АГ и ИзбМТ в 4 раза выше, чем у не имеющих этого сочетания ФР (в 2,43 раза среАи мужчин и 11,12 раз среди женщин; $\mathrm{p}<0,001)$. Повышение риска СС смертности наблюдалось во всех поло-возрастных группах, кроме мужчин 40-59 мет (табл. 2).

Сочетание АГ и ГТГ увекичивает риск смертности от всех причин в 2,83 раза (в 2,10 раза среди мужчин и в 3,74 раза среАи женщин; $\mathrm{p}<0,001)$, смертности от СС3 - в 5,06 раза (в 2,91 раза среди мужчин и в 9,4 раза среди женщин; $\mathrm{p}<0,001)$. Высокие показатели ОР общей смертности наблюАались во всех возрастных группах общей когорты, а также среди женщин. СреАи мужчин в возрастных группах результаты не Аостигали статистической значимости, что может быть обусловлено небольшим числом наблюдений. Увеличение риска преждевременной СС смертности отмечалось во всех поло-возрастных группах, за исключением мужчин 40-59 мет (табц. 3, 4).

Сочетание ИзбМТ и ГТГ увекичивает вероятность прежАевременной смерти в 1,73 раза $(\mathrm{p}<0,001)$ по сравнению с мицами с нормальной массой тела без ГТГ. ОАнако значимым ФР такая комбинация оказалась только Аля женщин, повышая ОР общей смертности до 3,35 (p<0,001) (табл. 5). ОР смертности от ССЗ в случае сочетания этих ФР повышается в 2,99 раза (в 2,01 раза среди мужчин, в 6,98 раз среди женщин; $\mathrm{p}<0,05)$, преимущественно за счет мужчин и женщин миаАших возрастных групп (табц. 6).

При изучении Аополнительного риска общей смертности, ассоциированной с ИзбМТ, у миц с АГ показано, что риск прежАевременной смерти у женщин 20-59 ^ет с сочетанием АГ и ИзбМТ в 3,23 раза выше, чем у женщин с АГ, имеющих нормальную массу тела $(\mathrm{p}<0,05)$. ОАнако в связи с малым числом респонденток в группах сравнения получены широкие границы доверительного интервала (95\% АИ: 0,84-12,30), и утвержАать о статистической значимости этих резумьтатов бымо бы некорректно. В Аругих поло-возрастных группах результаты не имели статистической значимости. Недостоверными оказались и результаты, касающиеся изучения Аополнительного риска СС смертности от ИзбМТ у миц, имеющих повышенные значения АА.

Анализ Аополнительного риска смертности, ассоциированной с ГТГ, у миц, страдающих АГ, показал, что повышенный уровень ТГ увекичивает риск общей смертности у киц с $A Г$ в 1,51 раза $(\mathrm{p}<0,05)$, преимущественно за счет старшей возрастной группы $(\mathrm{OP}=1,49 ; \mathrm{p}<0,05)$. При гендерном анамизе увеличение риска смертности в связи с ГТГ у миц, имеющих повышенные значения АА, обнаружено только среАи женщин (OP=1,80, $\mathrm{p}<0,05$; в старшей возрастной группе $\mathrm{OP}=1,80, \mathrm{p}<0,05)$ (табц. 7). Повышение Аополнительного 
Табмица 3. Относитемьный риск общей смертности у миц с сочетанием АГ и ГТГ

\begin{tabular}{|c|c|c|c|c|c|c|c|c|c|}
\hline \multirow{2}{*}{ Пом } & \multirow{2}{*}{ Возраст } & \multirow{2}{*}{$\begin{array}{c}\text { АГ } \\
\text { и ГТГ }\end{array}$} & \multirow{2}{*}{$\mathbf{N}$} & \multicolumn{2}{|c|}{ Общая смертность } & \multirow{2}{*}{$x^{2}$} & \multirow{2}{*}{$\mathbf{p}$} & \multirow{2}{*}{ OP } & \multirow{2}{*}{ 95\% АИ } \\
\hline & & & & $\mathbf{n}$ & $\%$ & & & & \\
\hline \multirow{6}{*}{$\begin{array}{l}\text { Общая } \\
\text { когорта }\end{array}$} & \multirow{2}{*}{ 20-39 мет } & Нет & 541 & 57 & 10,5 & \multirow[b]{2}{*}{7,66} & \multirow[b]{2}{*}{$<0,01$} & 1 & \multirow[b]{2}{*}{$1,48-6,74$} \\
\hline & & Есть & 15 & 5 & 33,3 & & & 3,16 & \\
\hline & \multirow{2}{*}{$40-59$ мет } & Нет & 303 & 83 & 27,4 & \multirow[b]{2}{*}{10,31} & \multirow[b]{2}{*}{$<0,01$} & 1 & \multirow[b]{2}{*}{$1,27-2,38$} \\
\hline & & Есть & 65 & 31 & 47,7 & & & 1,74 & \\
\hline & \multirow{2}{*}{$20-59$ мет } & Нет & 844 & 140 & 16,6 & \multirow[b]{2}{*}{41,45} & \multirow[b]{2}{*}{$<0,001$} & 1 & \multirow[b]{2}{*}{$2,13-3,76$} \\
\hline & & Есть & 80 & 36 & 45,0 & & & 2,83 & \\
\hline \multirow{6}{*}{ Мужчины } & \multirow{2}{*}{ 20-39 мет } & Нет & 198 & 34 & 17,2 & \multirow[b]{2}{*}{3,02} & \multirow[b]{2}{*}{0,08} & 1 & \multirow[b]{2}{*}{$1,01-6,19$} \\
\hline & & Есть & 7 & 3 & 42,9 & & & 2,50 & \\
\hline & \multirow{2}{*}{$40-59$ мет } & Нет & 132 & 49 & 37,1 & \multirow[b]{2}{*}{1,79} & \multirow[b]{2}{*}{$>0,05$} & 1 & \multirow[b]{2}{*}{$0,89-2,03$} \\
\hline & & Есть & 32 & 16 & 50,0 & & & 1,35 & \\
\hline & \multirow{2}{*}{ 20-59 мет } & Нет & 330 & 83 & 25,2 & \multirow[b]{2}{*}{11,93} & \multirow[b]{2}{*}{$<0,001$} & 1 & \\
\hline & & Есть & 39 & 19 & 48,7 & & & 2,10 & $1,44-3,04$ \\
\hline & (20 20 & Нет & 343 & 23 & 6,7 & & & 1 & \\
\hline & $20-39 \wedge е т$ & Есть & 8 & 2 & 25,0 & 3,96 & $<0,05$ & 3,73 & $1,05-13,19$ \\
\hline & $40-50$ & Нет & 171 & 34 & 19,9 & & & 1 & \\
\hline Женщины & $40-59 \Lambda е т$ & Есть & 33 & 15 & 45,5 & 9,91 & $<0,01$ & 2,29 & $1,41-3,69$ \\
\hline & & Нет & 514 & 57 & 11,1 & & & 1 & \\
\hline & 20-59 мет & Есть & 41 & 17 & 41,58 & 30,23 & $<0,001$ & 3,74 & $2,41-5,80$ \\
\hline
\end{tabular}

риска СС смертности, ассоциированной с ГТГ, у миц с АГ наблюдалось в общей когорте $(\mathrm{OP}=2,04 ; \mathrm{p}<0,01)$, преимущественно за счет ммадшей возрастной группы $(\mathrm{OP}=3,83$; $\mathrm{p}<0,01)$, а также среди женщин 20-59 мет $(\mathrm{OP}=2,17 ; \mathrm{p}<0,05)$ и мужчин 20-39 мет $(\mathrm{OP}=4,03 ; \mathrm{p}<0,05)$.

Анализ Аополнительного риска смертности, ассоциированной с ГТГ, у миц, имеющих ИзбМТ, показал, что повышенный уровень ТГ увеличивает риск общей смертности в 1,53 раза по сравнению с мицами, имеющими ИзбМТ без ГТГ $(\mathrm{p}<0,01)$. При гендерном анализе дополнительный риск, ассоциированный с ГТГ, выявлен только Аля женщин $(\mathrm{OP}=1,63$; $\mathrm{p}<0,05)$. При анализе по возрастным группам обнаружено повышение ОР смертности от ГТГ у женщин 40-59 мет с ИзбМТ (OP=1,56 среди женщин; $\mathrm{p}<0,05)$. В старшей возрастной группе общей когорты дополнительный риск общей смертности равен 1,35, однако $\mathrm{p}=0,05$. Амя миц моложе 40 мет результаты носят скучайный характер (табл. 8). При изучении Аополнительного риска сердечно-сосудистой смерт-

Таблица 4. Относительный риск серАечно-сосудистой смертности миц с сочетанием АГ и ГТГ

\begin{tabular}{|c|c|c|c|c|c|c|c|c|c|}
\hline \multirow{2}{*}{ Пом } & \multirow{2}{*}{ Возраст } & \multirow{2}{*}{$\begin{array}{c}\text { АГ } \\
\text { и ГТГ }\end{array}$} & \multirow{2}{*}{$\mathbf{N}$} & \multicolumn{2}{|c|}{ Смертность от ССЗ } & \multirow{2}{*}{$\chi^{2}$} & \multirow{2}{*}{ p } & \multirow{2}{*}{ OP } & \multirow{2}{*}{ 95\% АИ } \\
\hline & & & & $\mathbf{n}$ & $\%$ & & & & \\
\hline \multirow{6}{*}{$\begin{array}{l}\text { Общая } \\
\text { попумяция }\end{array}$} & \multirow{2}{*}{ 20-39 ^ет } & Нет & 541 & 12 & 2,2 & \multirow[b]{2}{*}{47,67} & \multirow[b]{2}{*}{$<0,001$} & 1 & \multirow[b]{2}{*}{$6,06-37,28$} \\
\hline & & Есть & 15 & 5 & 33,3 & & & 15,03 & \\
\hline & \multirow{2}{*}{$40-59 \Lambda е т$} & Нет & 303 & 36 & 11,9 & \multirow[b]{2}{*}{10,69} & \multirow[b]{2}{*}{$<0,01$} & 1 & \multirow[b]{2}{*}{$1,42-3,84$} \\
\hline & & Есть & 65 & 18 & 27,7 & & & 2,33 & \\
\hline & \multirow{2}{*}{$20-59$ мет } & Нет & 844 & 48 & 5,7 & \multirow[b]{2}{*}{54,79} & \multirow[b]{2}{*}{$<0,001$} & 1 & \multirow[b]{2}{*}{$3,25-7,86$} \\
\hline & & Есть & 80 & 23 & 28,8 & & & 5,06 & \\
\hline \multirow{6}{*}{ Мужчины } & \multirow{2}{*}{ 20-39 ^ет } & Нет & 198 & 8 & 4,0 & \multirow[b]{2}{*}{20,06} & \multirow[b]{2}{*}{$<0,001$} & 1 & \multirow[b]{2}{*}{$3,56-31,61$} \\
\hline & & Есть & 7 & 3 & 42,9 & & & 10,61 & \\
\hline & \multirow{2}{*}{$40-59$ «ет } & Нет & 132 & 24 & 18,2 & \multirow[b]{2}{*}{0,76} & \multirow[b]{2}{*}{0,383} & 1 & \multirow[b]{2}{*}{$0,68-2,77$} \\
\hline & & Есть & 32 & 8 & 25,0 & & & 1,38 & \\
\hline & \multirow{2}{*}{ 20-59 ^ет } & Нет & 330 & 32 & 9,7 & \multirow[b]{2}{*}{11,61} & \multirow[b]{2}{*}{$<0,001$} & 1 & \\
\hline & & Есть & 39 & 11 & 28,2 & & & 2,91 & $1,60-5,30$ \\
\hline & $20-39$ гет & Нет & 343 & 4 & 1,2 & & & 1 & \\
\hline & $20-27, \alpha е т$ & Есть & 8 & 2 & 25,0 & 26,43 & $<0,001$ & 21,44 & $4,57-100,56$ \\
\hline Женшины & $40-50$ & Нет & 171 & 12 & 7,0 & & & 1 & \\
\hline Кенщины & $40-59 \Lambda е т$ & Есть & 33 & 10 & 30,3 & 15,59 & $<0,001$ & 4,32 & $2,04-9,16$ \\
\hline & & Нет & 514 & 16 & 3,1 & & & 1 & \\
\hline & $20-59 \Lambda \mathrm{eT}$ & Есть & 41 & 12 & 29,3 & 54,22 & $<0,001$ & 9,4 & $4,78-18,51$ \\
\hline
\end{tabular}


Таблица 5. Относительный риск общей смертности в зависимости от сочетания ГТГ и ИзбМТ

\begin{tabular}{|c|c|c|c|c|c|c|c|c|c|}
\hline \multirow{2}{*}{ Пом } & \multirow{2}{*}{ Возраст } & \multirow{2}{*}{$\begin{array}{c}\text { ГТГ } \\
\text { и ИзбМТ }\end{array}$} & \multirow{2}{*}{$\mathbf{N}$} & \multicolumn{2}{|c|}{ Общая смертность } & \multirow{2}{*}{$\chi^{2}$} & \multirow{2}{*}{$\mathbf{p}$} & \multirow{2}{*}{ OP } & \multirow{2}{*}{ 95\% АИ } \\
\hline & & & & $\mathbf{n}$ & $\%$ & & & & \\
\hline \multirow{5}{*}{$\begin{array}{l}\text { Общая } \\
\text { когорта }\end{array}$} & \multirow{2}{*}{ 20-39 кет } & Нет & 340 & 43 & 12,6 & \multirow[b]{2}{*}{1,83} & \multirow[b]{2}{*}{$>0,05$} & 1 & \multirow[b]{2}{*}{$0,83-2,89$} \\
\hline & & Есть & 51 & 10 & 19,6 & & & 1,55 & \\
\hline & \multirow{2}{*}{$40-59$ мет } & Нет & 135 & 44 & 32,6 & \multirow[b]{2}{*}{0,57} & \multirow[b]{2}{*}{$>0,05$} & 1 & \multirow[b]{2}{*}{$0,81-1,60$} \\
\hline & & Есть & 113 & 42 & 37,2 & & & 1,14 & \\
\hline & 20-59 кет & Нет & 475 & 87 & 18,3 & 12,84 & $<0,001$ & 1 & $1,29-2,32$ \\
\hline \multirow{5}{*}{ Мужчины } & \multirow{2}{*}{ 20-39 мет } & Нет & 153 & 35 & 22,9 & \multirow[b]{2}{*}{0,31} & \multirow[b]{2}{*}{$>0,05$} & 1 & \multirow[b]{2}{*}{$0,61-2,45$} \\
\hline & & Есть & 25 & 7 & 28,0 & & & 1,22 & \\
\hline & \multirow{2}{*}{$40-59$ мет } & Нет & 79 & 32 & 40,5 & \multirow[b]{2}{*}{0,0} & \multirow[b]{2}{*}{$>0,05$} & 1 & \multirow[b]{2}{*}{$0,65-1,52$} \\
\hline & & Есть & 52 & 21 & 40,4 & & & 1,0 & \\
\hline & $20-59$ мет & Нет & 232 & 67 & 28,9 & 1,52 & $>0,05$ & 1 & \\
\hline Женщины & $40-59 \Lambda е т$ & Есть & 61 & 21 & 34,4 & 2,44 & $>0,05$ & 1,61 & $0,87-2,96$ \\
\hline & $20<0$ & Нет & 243 & 20 & 8,2 & & & 1 & \\
\hline & $20-59 \Lambda е т$ & Есть & 87 & 24 & 27,6 & 20,77 & $<0,001$ & 3,35 & $1,95-5,75$ \\
\hline
\end{tabular}

ности, ассоциированной с ГТГ, у миц с ИзбМТ обнаружено, что ГТГ увеличивает риск СС смертности в 2,18 раза (в 3,13 раза в младшей возрастной группе и в 1,7 раза в старшей возрастной группе; $\mathrm{p}<0,05)$. При гендерном анализе установлено повышение Аополнительного риска СС смертности, ассоциированной с ГТГ, у женщин, имеющих ИзбМТ (OP=2,41; $\mathrm{p}<0,01)$, преимущественно за счет старшей возрастной группы $(\mathrm{OP}=1,94 ; \mathrm{p}<0,05)$. У мужчин значения ОР составили 1,77 $(\mathrm{p}=0,05)$.

\section{ОбсУЖАение}

Итоги 27-летнего проспективного наблюдения показали, что АГ оказывает несомненное влияние на формирование общей и СС смертности, что наблюАалось во всех поло-возрастных группах за исключением мужчин 40-59 мет, у которых результаты, касающиеся формирования риска смертности от ССЗ, оказались статистически незначимыми. Это согласуется с результатами многих отечественных и зарубежных исследований. Так, в 6-летнем исследовании во Франции

Табмица 6. Относитемьный риск сердечно-сосудистой смертности в зависимости от сочетания ГТГ и ИзбМТ

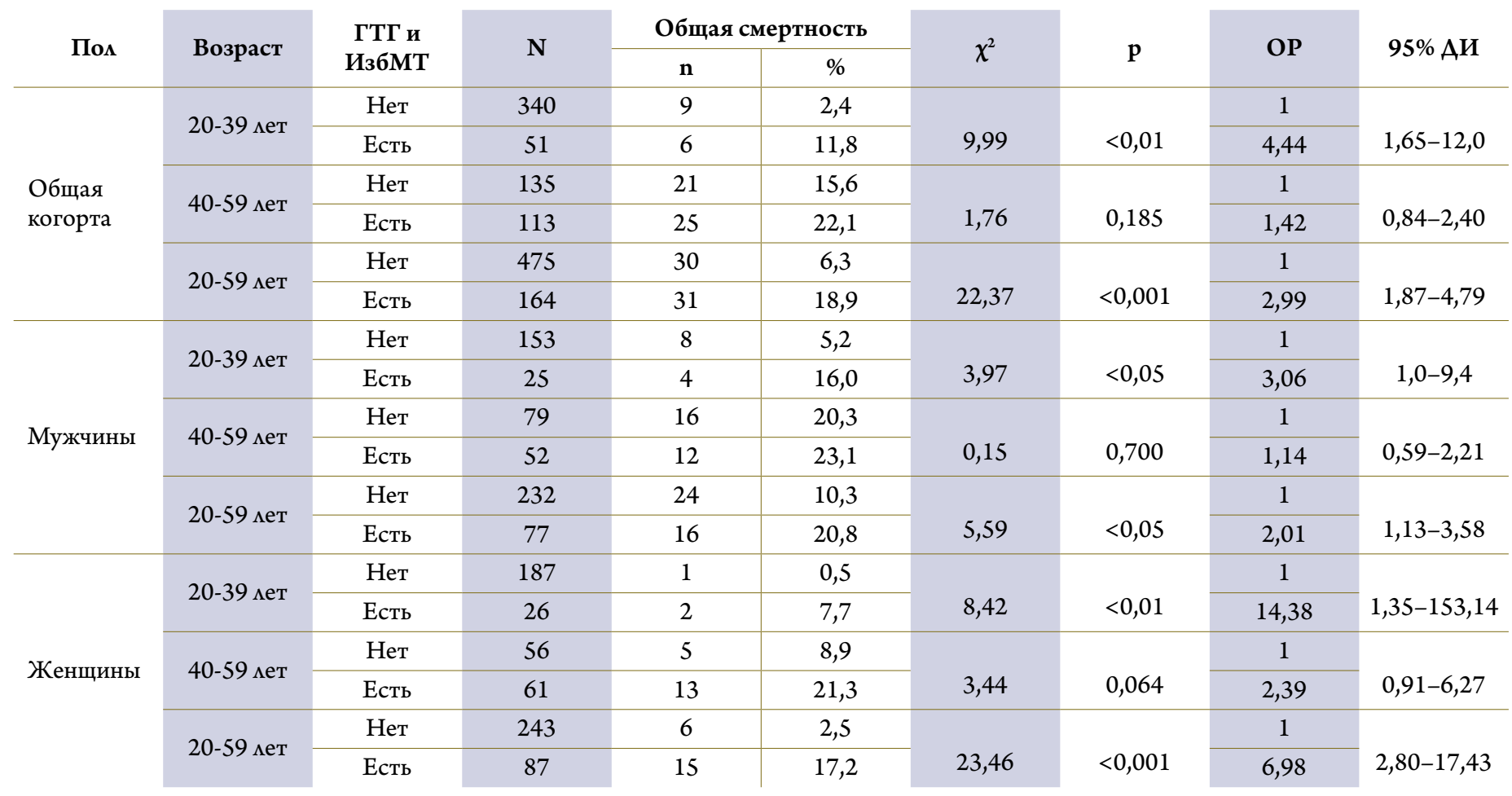


Таблица 7. Аополнительный риск общей смертности, ассоциированной с ГТГ, у миц с АГ

\begin{tabular}{|c|c|c|c|c|c|c|c|c|c|}
\hline \multirow{2}{*}{ Пом } & \multirow{2}{*}{ Возраст } & \multirow{2}{*}{$\begin{array}{c}Г Т Г ~ \\
\text { у Аиц с АГ }\end{array}$} & \multirow{2}{*}{$\mathbf{N}$} & \multicolumn{2}{|c|}{ Общая смертность } & \multirow{2}{*}{$\chi^{2}$} & \multirow{2}{*}{$\mathbf{p}$} & \multirow{2}{*}{ OP } & \multirow{2}{*}{ 95\% АИ } \\
\hline & & & & $\mathbf{n}$ & $\%$ & & & & \\
\hline \multirow{6}{*}{$\begin{array}{l}\text { Общая } \\
\text { когорта }\end{array}$} & \multirow{2}{*}{$20-39$ кет } & Нет & 92 & 24 & 26,1 & \multirow[b]{2}{*}{0,34} & \multirow[b]{2}{*}{$>0,05$} & 1 & \multirow[b]{2}{*}{$0,58-2,83$} \\
\hline & & Есть & 15 & 5 & 33,3 & & & 1,28 & \\
\hline & \multirow{2}{*}{$40-59 \Lambda е т$} & Нет & 163 & 52 & 31,9 & \multirow[b]{2}{*}{5,0} & \multirow[b]{2}{*}{$<0,05$} & 1 & \multirow[b]{2}{*}{$1,06-2,10$} \\
\hline & & Есть & 65 & 31 & 47,7 & & & 1,49 & \\
\hline & \multirow{2}{*}{$20-59 \Lambda е т$} & Нет & 255 & 76 & 29,8 & \multirow[b]{2}{*}{6,32} & \multirow[b]{2}{*}{$<0,05$} & 1 & \multirow[b]{2}{*}{$1,11-2,05$} \\
\hline & & Есть & 80 & 36 & 45,0 & & & 1,51 & \\
\hline \multirow{6}{*}{ Мужчины } & \multirow{2}{*}{ 20-39 мет } & Нет & 47 & 16 & 34,0 & \multirow[b]{2}{*}{0,21} & \multirow[b]{2}{*}{$>0,05$} & 1 & \multirow[b]{2}{*}{$0,49-3,23$} \\
\hline & & Есть & 7 & 3 & 42,9 & & & 1,26 & \\
\hline & \multirow{2}{*}{$40-59$ мет } & Нет & 60 & 26 & 43,3 & \multirow[b]{2}{*}{0,37} & \multirow[b]{2}{*}{$>0,05$} & 1 & \multirow[b]{2}{*}{$0,73-1,81$} \\
\hline & & Есть & 32 & 16 & 50,0 & & & 1,15 & \\
\hline & \multirow{2}{*}{$20-59$ кет } & Нет & 107 & 42 & 39,3 & \multirow[b]{2}{*}{1,05} & \multirow[b]{2}{*}{$>0,05$} & 1 & \\
\hline & & Есть & 39 & 19 & 48,7 & & & 1,24 & $0,83-1,85$ \\
\hline & & Нет & 45 & 8 & 17,8 & & & 1 & \\
\hline & 20-39 мет & Есть & 8 & 2 & 25,0 & 0,23 & $>0,05$ & 1,41 & $0,36-5,45$ \\
\hline Женшини & $40-50$ & Нет & 103 & 26 & 25,2 & & & 1 & \\
\hline Женщины & 40-59 мет & Есть & 33 & 15 & 45,5 & 4,85 & $<0,05$ & 1,80 & $1,09-2,97$ \\
\hline & $20-59$ рат & Нет & 148 & 34 & 23,0 & & & 1 & \\
\hline & $20-59 \wedge е т$ & Есть & 41 & 17 & 41,58 & 5,57 & $<0,05$ & 1,80 & $1,13-2,88$ \\
\hline
\end{tabular}

Таблица 8. Аополнительный риск общей смертности, ассоциированной с ГТГ, у миц с ИзбМТ

\begin{tabular}{|c|c|c|c|c|c|c|c|c|c|}
\hline \multirow{2}{*}{ Пом } & \multirow{2}{*}{ Возраст } & \multirow{2}{*}{$\begin{array}{l}\text { ГТГ у Аиц } \\
\text { с ИзбМТ }\end{array}$} & \multirow{2}{*}{$\mathbf{N}$} & \multicolumn{2}{|c|}{ Общая смертность } & \multirow{2}{*}{$x^{2}$} & \multirow{2}{*}{$\mathbf{p}$} & \multirow{2}{*}{ OP } & \multirow{2}{*}{ 95\% АИ } \\
\hline & & & & $\mathbf{n}$ & $\%$ & & & & \\
\hline \multirow{6}{*}{$\begin{array}{l}\text { Общая } \\
\text { когорта }\end{array}$} & \multirow{2}{*}{$20-39$ мет } & Нет & 293 & 38 & 13,0 & \multirow[b]{2}{*}{1,59} & \multirow[b]{2}{*}{$>0,05$} & 1 & \multirow[b]{2}{*}{$0,81-2,84$} \\
\hline & & Есть & 51 & 10 & 19,6 & & & 1,51 & \\
\hline & \multirow{2}{*}{ 40-59 мет } & Нет & 331 & 91 & 27,5 & \multirow[b]{2}{*}{3,76} & \multirow[b]{2}{*}{$=0,05$} & 1 & \multirow[b]{2}{*}{$1,00-1,81$} \\
\hline & & Есть & 113 & 42 & 37,2 & & & 1,35 & \\
\hline & \multirow{2}{*}{$20-59 \Lambda е т$} & Нет & 624 & 129 & 20,7 & \multirow[b]{2}{*}{8,94} & \multirow[b]{2}{*}{$<0,01$} & 1 & \multirow[b]{2}{*}{$1,17-2,01$} \\
\hline & & Есть & 164 & 52 & 31,7 & & & 1,53 & \\
\hline \multirow{6}{*}{ Мужчины } & \multirow{2}{*}{ 20-39 мет } & Нет & 92 & 15 & 16,3 & \multirow[b]{2}{*}{1,76} & \multirow[b]{2}{*}{$>0,05$} & 1 & \multirow[b]{2}{*}{$0,79-3,75$} \\
\hline & & Есть & 25 & 7 & 28,0 & & & 1,72 & \\
\hline & \multirow{2}{*}{$40-59 \Lambda е т$} & Нет & 113 & 43 & 38,1 & \multirow[b]{2}{*}{0,08} & \multirow[b]{2}{*}{$>0,05$} & 1 & \multirow[b]{2}{*}{$0,71-1,59$} \\
\hline & & Есть & 52 & 21 & 40,4 & & & 1,06 & \\
\hline & \multirow{2}{*}{$20-59 \Lambda е т$} & Нет & 205 & 58 & 28,3 & \multirow[b]{2}{*}{1,72} & \multirow[b]{2}{*}{$>0,05$} & 1 & \\
\hline & & Есть & 77 & 28 & 36,4 & & & 1,29 & $0,89-1,86$ \\
\hline & 30 & Нет & 201 & 23 & 11,4 & & & 1 & \\
\hline & $20-39 \Lambda е т$ & Есть & 26 & 3 & 11,5 & 0,0 & $>0,05$ & 1,01 & $0,33-3,13$ \\
\hline Женшины & & Нет & 218 & 48 & 22,0 & & & 1 & \\
\hline Женщины & $40-59 \wedge е т$ & Есть & 61 & 21 & 34,4 & 3,94 & $<0,05$ & 1,56 & $1,02-2,40$ \\
\hline & & Нет & 419 & 71 & 16,9 & & & 1 & \\
\hline & $20-59$ мет & Есть & 87 & 24 & 27,6 & 5,35 & $<0,05$ & 1,63 & $1,09-2,43$ \\
\hline
\end{tabular}

показано, что риск общей и СС смертности у миц с АГ выше, чем у миц с нормальным АА (в 1,31 и 2,51 раза, соответственно) [14]. А в Иранском когортном исследовании установмена прямая взаимосвязь межАу значениями АА и вероятностью прежАевременной смертности от ССЗ и от всех причин [15].

Из результатов однофакторного анализа следовало, что ИзбМТ и ГТГ также в значительной степени повышают риск как общей, так и СС смертности. ОАнако многофакторный анализ не выявия значимого вмияния ИзбМТ и ГТГ на формирование общей и СС смертности. Это может быть обусловлено связью ИзбМТ с такими важными ФР, как АГ и возраст. Известно, что ИзбМТ может способствовать развитию АГ, ГТГ, Аислипопротеидемии, инсулинорезистентности и усилению их атерогенного эффекта. Возраст также имеет немаловажное значение, поскольку чем Алительнее воздействие ФР, тем более выраженный патогенный эффект, в том числе атерогенный, им оказывается. Неоднозначность результатов одно- и многофакторного анализов в том числе может быть объяснена используемой в статистических анамизах множественной станАартизацией, при этом истинный 
вклад ИзбМТ и ГТГ в формирование риска прежАевременной смертности может оказываться неАооцененным.

В связи с этим Аля выявления самостоятельного риска исследуемых преАикторов изучены вмияния сочетаний ИзбМТ и ГТГ с АГ, а также ГТГ с ИзбМТ и Амя каждой пары ФР рассчитаны показатели Аополнительного риска смертности. При изучении Аополнительного риска общей смертности в связи с ИзбМТ у миц с АГ увеличение ОР смертности наблюдалось только у женщин (OP=3,23; $\mathrm{p}<0,05)$, однако малое число респонденток в группах сравнения не Аает возможности с уверенностью говорить о значимости полученных результатов (95\% АИ: 0,84-12,30). Тем не менее анализ вклада ИзбМТ в формирование АГ, выполненный на промежуточном (семнадцатилетнем) этапе исследования, обнаружик увекичение частоты $А Г$ и повышение уровней АА у миц, у которых отмечалось нарастание массы тела до степени избыточной, и уменьшение этих показателей у тех, чья масса тела снизияась до нормальных значений. А средние значения САА и ААА у мужчин и женщин, имеющих ИзбМТ при первичном обследовании, оказались достоверно выше, чем у миц, у которых ИзбМТ сформировалась в период 17-летнего наблюдения [16]. Кроме того, обращает на себя внимание высокая распространенность ИзбМТ у миц с АГ: 81,2\% респондентов с повышенным АА при первичном исследовании имели ИзбМТ, а среди женщин - 90,4\%. Все это свидетельствует о значимой роли ИзбМТ в патогенезе $А Г$, а также о ее важном значении в формировании показателей смертности, которые реализуются не самостоятельно, а посреАством вкцада в развитие АГ.

Анализ риска смертности у миц с сочетанием АГ и ГТГ показал, что повышенный уровень ТГ Аополнительно увемичивает риск смертности у миц, страдающих АГ, преимущественно за счет женщин и мищ старше 40 мет. Кроме того, обнаружен Аополнительный риск смертности в связи с ГТГ у миц, имеющих ИзбМТ. Из этого может слеАовать, что прогностически неблагоприятным в отношении смертности явцяется не изолированное повышение уровней ТГ, а сочетание ГТГ с ИзбМТ и АГ. Это положение позвомяет преАположить размичия ТГ по вкАюченным в их состав жирным кислотам, а также различающемся вкладе ТГ и жирных кисмот в формирование мипидного спектра при изолированной и сочетанной ГТГ.

Таким образом, можно сделать вывоА о наличии тесной патогенетической взаимосвязи изучаемых ФР, сочетание которых не просто суммирует эффекты каждого из ФР в отАельности, а имеет синергическое, взаимно усиливающее воздействие в генезе смертности.

Учитывая, что изучаемые ФР являются модифицируемыми, можно ожидать снижения СС заболеваемости и смертности при условии успешного проведения профилактических мероприятий. При их планировании важно учитывать выявменную нами высокую распространенность ИзбМТ и значимый вклаА этого фактора в формирование риска смертности

\section{Тригрим}

торасемид

Три доказанных

преимущества торасемида

Снижает сердечно-сосудистую

смертность $^{7}$

Замедляет развитие фиброза миокарда и сосудов ${ }^{2}$

Снижает риск гипокалемии, метаболически нейтрален ${ }^{1,2}$
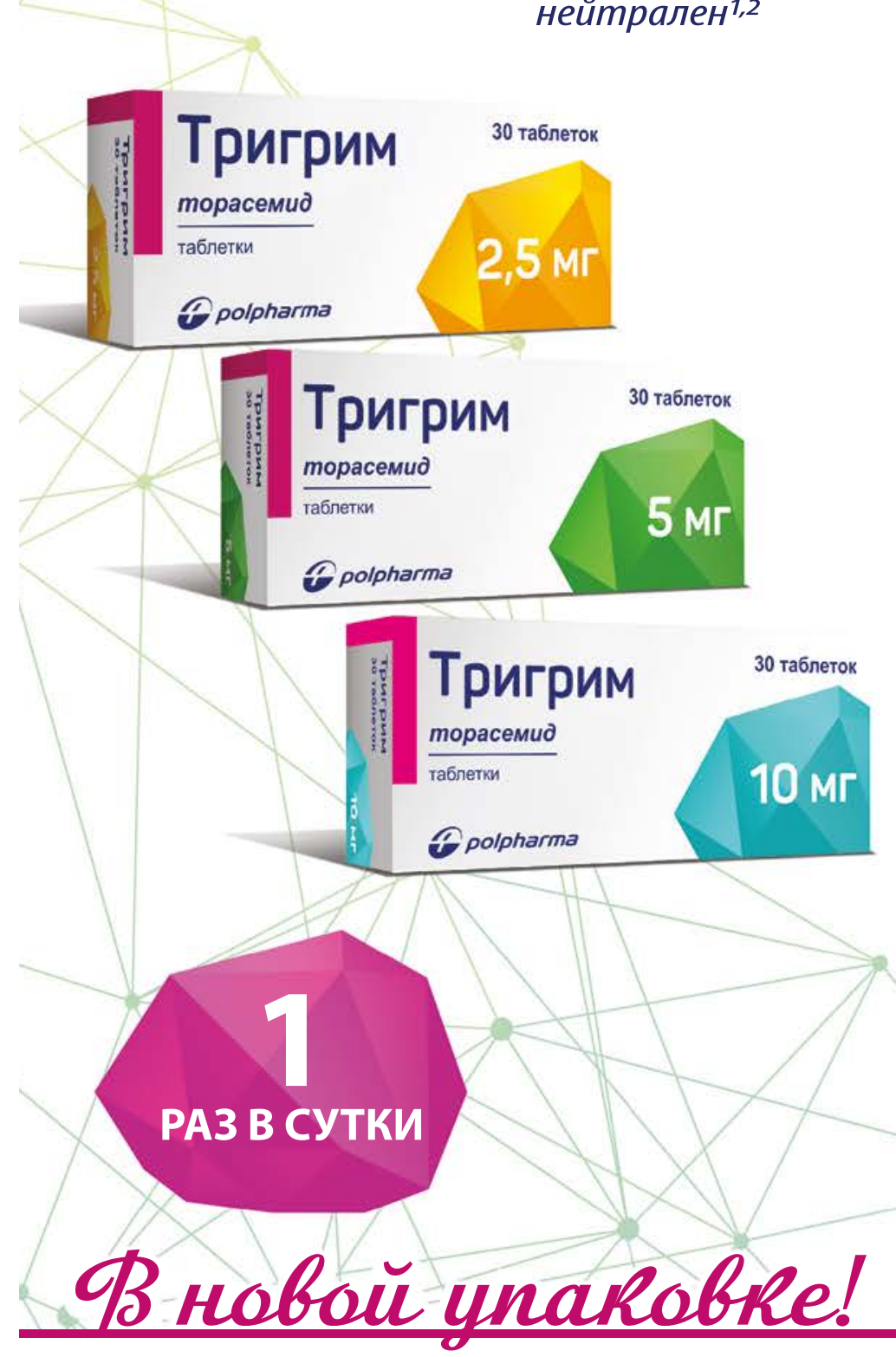

- Cosin J., Diez J. and TORIC investigators. Torasemide in chronic heart falure: results of the TORIC study // Eur. J. Heart Fail/ - 2002. - 4(4). - 507-13.

2 - Lopez B, Effects of loop diuretics on myocardial fibrosis and collagen type I tumover in chronic heart falure. Journal of the American College of Cardiology Vol. 43, No/ 11, 2004;2028-35 
у миц молодого возраста, особенно женщин. Большое значение Аля предупреждения кардиоваскулярных заболеваний и снижения риска прежАевременной смертности будет иметь своевременное обнаружение случаев ГТГ, особенно среАи миц с ИзбМТ и АГ, и последующее применение комплекса профилактических мер, направленных на снижение негативного эффекта этих факторов.

\section{Закмючение}

По результатам 27-летнего проспективного исследования выявмено независимое вмияние АГ на формирование риска общей и СС смертности. ГТГ в сочетании с АГ увекичивает риск смерти от всех причин в 2,8 раза, смерти от СС3 5,1 раз; при этом Аополнительный риск общей смертности в связи с ГТГ у мищ с АГ составим $1,5, \mathrm{CC}-2$. Сочетание ГТГ и ИзбМТ увеличивает риск смерти в 1,7 раза, смерти от СС3 в 3 раза; Аополнительный риск общей смертности в связи с ГТГ у миц с ИзбМТ - 1,5, СС - 2,2. Также установлено, что сочетание АГ и ИзбМТ увекичивает риск прежАевременной смерти в 2,2 раза.

\section{Благодарности}

Авторы выражают глубокую благодарность сотрудникам кафеАры факультетской терапии ФГБОУ ВО «СибГМУ» Минзарава РФ профессору, академику РАН Р.С. Карпову; Аоценту В.В. Образцову; Аоценту Б.А. Троценко; ассистенту И. В. Цымбалюку за активное участие и помощь в наборе фактического материала.

\section{Конфликт интересов не заявляется.}

2016;56(7):63-71. [Russian: Карпов Ю.А. Распространенность гипертриглицеридемии: новые всероссийские Аанные. Исследование PROMETHEUS. Кардиология. 2016;56(7):63-71]. DOI: 10.18565/ cardio.2016.7.63-71

11. Ezhov M.V., Sergienko I.V., Aronov D.M., Arabidze G.G., Akhmedzhanov N.M., Bazhan S.S. et al. Diagnostics and correction of lipid metabolism disorders for the prevention and treatment of atherosclerosis. Revision VI. Atherosclerosis and Dyslipidemias. 2017;3(28):5-22. [Russian: Ежов М.В., Сергиенко И.В., Аронов А.М., АрабиАзе Г.Г. АхмеАжанов Н.М., Бажан С.С. и Ар. Аиагностика и коррекция нарушений мипидного обмена с целью профилактики и мечения атероскмероза. Российские рекомендации VIпересмотр.Атероскмероз и Аислипидемии. 2017;3(28):5-22]

12. Ivanova A.Yu., Dolgalev I.V. Impact of Arterial Hypertension on the Formation of the Risk of Mortality. Results of a 27-Year Prospective Study. Kardiologiia. 2018;17(9):5-11. [Russian: Иванова А.Ю., Аолгалёв И.В. Вмияние артериальной гипертензии на формирование риска смертности по результатам 27-цетнего проспективного исследования. Кардиология. 2018;58(9):5-11]. DOI: 10.18087/cardio.2018.9.10168

13. Ivanova A.Yu., Dolgalev I.V. Impact of overweight and obesity on mortality (according to the results of a 27-year prospective study). Preventive Medicine. 2017;20(3):34-9. [Russian: Иванова А. Ю., Аолгалёв И. В. ВАияние избыточной массы тела и ожирения на смертность (по результатам 27-летнего проспективного исследования). Профилактическая медицина. 2017;20(3):34-9]. DOI: 10.17116/ profmed201720334-39

14. Pannier B, Thomas F, Hanon O, Czernichow S, Lemogne C, Simon T et al. Individual 6-year systolic blood pressure change and impact on cardiovascular mortality in a French general population. Journal of Human Hypertension. 2016;30(1):18-23. DOI: 10.1038/jhh.2015.44

15. Sepanlou SG, Sharafkhah M, Poustchi H, Malekzadeh MM, Etemadi A, Khademi $\mathrm{H}$ et al. Hypertension and mortality in the Golestan Cohort Study: A prospective study of 50000 adults in Iran. Journal of Human Hypertension. 2016;30(4):260-7. DOI: 10.1038/jhh.2015.57

16. Dolgalyov I.V., Obraztsov V.V., Tsimbalyuk I.V., Konko T.Yu., Trotsenko B.A., Karpov R.S. Dynamics of arterial hypertension depending on change of weight of a body, according to the results of a 17-year prospective study. Bulletin of Siberian Medicine. 2012;11(1):150-5. [Russian: Аолгалёв И.В., Образцов В.В., Цимбалюк И.В., Конько Т.Ю., Троценко Б.А., Карпов Р.С. Аинамика артериальной гипертонии в зависимости от изменения массы тела по результатам 17-летнего проспективного иссмедования. Бюмметень сибирской медицины. 2012;11(1):150-5]

Статья поступима 12.12.18 (Received 12.12.18) 